\title{
RESEARCH PAPER \\ CURRICULUM RELEVANCE AND GRADUATE CAREER: A TRACER STUDY OF CEMBA, CEMPA AND INDUSTRIAL MATHEMATICS GRADUATES
}

\author{
C. K. Osei, I. K. Dontwi, K. G. Otchere and A. A. Singye \\ Institute of Distance Learning, KNUST, Kumasi
}

\begin{abstract}
The study traced the graduates of CEMBA, CEMPA and MSc. Industrial Mathematics programmes in the distance learning mode at the Kwame Nkrumah University of Science and Technology (KNUST), Kumasi from 2010 to 2012. The descriptive survey method was used to assess the large and scattered graduate population. The main instrument used in gathering data was a questionnaire. A face to face interview with employers was also conducted in order to support data from graduate respondents. A total of 450 graduates participated in the study. The SPSS statistical software was used to generate results from the acquired quantitative data. The findings revealed that majority of the graduates in the three programmes were employed in the public sector, and mainly in the field of education. The Graduates found the content of their programme relevant to their career. The results also showed that job performance of graduates improved after their study. Work supervisors rated the graduates very high in terms of job performance indicators such as 'improved work competence' and 'team working ability'. Based on the findings, it is recommended that the Institute of Distance Learning and the Department of Mathematics utilise the findings/result of the study to review their curricula to meet workplace demands.
\end{abstract}

Keywords: IDL-KNUST, graduates, tracer study, job performance, relevance.

\section{INTRODUCTION}

It has become increasingly important for higher educational institutions to constantly assess their academic programmes. Such assessments provide appropriate feedback that could be used to revise course contents in order to produce graduates suitable for the job markets. An approach to achieve this end is through a tracer study. Graduate tracer study which is sometimes referred to as a follow-up or graduate/alumni survey provides the desirable information for determining the relationship between higher education and employment. Schomburg (2003) noted that by conducting a tracer survey of graduates, issues of biographical data on "where are your graduates 
now?" may supply information on income, job title, nature of employment and years of employment.

Tracer studies are means of maintaining curriculum relevance and providing targeted benefits to graduates to enhance the marketability of educational programmes (Balingbing, 2014). Aina and Moahi (1999) have explained that tracer studies enable the evaluation of results of the education and training provided by a particular institution to examine and evaluate the current and future career and employment prospects of graduates. Gines (2004) also pointed out that tracer studies are important sources of information to know what happened to graduates of academic programmes in Higher Education Institutions. Further he noted that the findings of tracer studies could be used as basis for further improving existing and or developing new teacher education curricula and implementation processes.

According to Boaduo et al. (2009) tracer studies also enable the contextualization of graduates of a particular university through a system that is dynamic and reliable in order to determine their life path or movement. It also enables the evaluation of the results of the education and training provided by a particular institution and examines and evaluates the current and future career and employment opportunities/prospects of graduates.

In the area of distance education, tracer studies of Open and Distance Learning (ODL) graduates can provide the information needed to reform educational programmes to bring about the fit between the requirements of the employment world and study. Further, 'ODL providers can use the information gathered to look for personal and professional advancement through ODL' (Millington, 2003).

Tracer studies have been reported by various researchers for decades and examples include the West and Central African Council for Agricultural Research and Development
(WECARD) Report (2010) in Ghana, Stilwell (2004) in South Africa, Anyanwu (2000) in Nigeria and Genoni et al. (2000) in Australia. In Ghana, a tracer study was conducted to follow-up on agricultural graduates from 1993 to 2008 , with the view of generating relevant information that could possibly feed into curricula review to ensure that agricultural training institutions are able to produce graduates better suited for the job markets. The key findings of the study included among others that the training of agricultural graduates tended to emphasize theories rather than the application of the theories, and that there was a mismatch between the knowledge and skills given to agricultural graduates and what was required by employers (WECARD Report, 2010). In South Africa, a tracer study conducted by Stilwell (2004) with the aim of surveying alumni perceptions of the postgraduate Information and Library Science programme at the University of Natal identified that the programme achieved its outcomes because it prepared alumni well for the work place.

A tracer study in Nigeria by Anyanwu (2000) followed-up on Agricultural and Arts graduates from the University of Nsukka, with the objective of generating better understanding of the transition from school to work as well as the extent to which knowledge acquired during their study was relevant to their jobs. The study found that majority of the graduates indicated that the knowledge and skills acquired were used in their current jobs. A tracer study of the MLIS programme at Curtin University of Technology, Australia found that the graduates from the MLIS programme were occupying jobs in sectors outside the realm of information work (Genoni et al., 2000).

Although the tracer studies provided information regarding graduates' employment, use of acquired knowledge and skills as well as perception of programmes' contents, most of them were based on information provided by graduate respondents with little or no information from employers of these graduates. This limits 
a holistic understanding of the link between education and work.

Various studies have reported on the need to bridge the gap between industry and higher education through the development of curricula that are industry-relevant so that the undergraduates are fully equipped with general transferable skills that will prepare them for future employment (Dickinson, 2000; and Bolton and Hyland, 2003).

The Institute of Distance Learning, Kwame Nkrumah University of Science and Technology (KNUST-IDL) was established in 2005 to deliver programmes of study both on-going and new ones from all colleges of the University in the distance learning mode. The Institute offers opportunities for workers and adults to pursue tertiary education. During the 2012/2013 academic year KNUST-IDL run a total of 12 undergraduate and 13 postgraduate programmes with a total student population of 10,450 . Among the postgraduate programmes are the Commonwealth Executive Master of Business Administration (CEMBA), the Commonwealth Executive Master of Public Administration (CEMPA), and the MSc. in Industrial Mathematics.

The CEMBA/CEMPA programmes were introduced in the 2007/2008 academic year under the license from the Commonwealth of Learning (COL) and are described as the flagship pro
Tracer study of IDL graduates in KNUST... 91

grammes of the KNUST-IDL. The Programmes' objectives were to meet the social and professional demands for management and public administration education at the postgraduate level; to develop human resources in various aspects of the areas of study, and to provide students with Masters Degrees in the study areas. Between 2010 and 2012, KNUST graduated 1,573 CEMBA and 159 CEMPA candidates (Table 1).

The MSc. Industrial Mathematics programme was introduced in the 2005/2006 academic year as a borrowed programme from the Department of Mathematics to be delivered in the distance learning mode. The main objective of the programme was to train highly skilled manpower capable of effectively formulating, analysing and computing solutions to mathematical models of industrial (Management) problems in a Developing Economy. KNUSTIDL has produced 204 post graduates in Industrial mathematicians between 2010 and 2012 (Table 1).

Even though KNUST-IDL staffs have conducted studies on different aspects of distance learning, there has been no assessment of graduate programmes that provide an accurate record of the current position and job responsibilities of graduates from the institute. Also there is no available information regarding the relationship between graduate programmes of study and graduates' current work and related

Table 1: Enrolment and graduation trends

\begin{tabular}{lcc}
\hline Programme & $\begin{array}{c}\text { Number admitted } \\
(\mathbf{2 0 0 8 - 2 0 1 0 )}\end{array}$ & $\begin{array}{c}\text { Number graduated } \\
(\mathbf{2 0 1 0 - 2 0 1 2})\end{array}$ \\
\hline CEMBA & 1,982 & 1,573 \\
CEMPA & 215 & 159 \\
MSc. Industrial Mathematics & 315 & 204 \\
Total & & $\mathbf{1 , 9 3 6}$ \\
\hline
\end{tabular}

Source: KNUST-IDL records 
competencies. The aim of the study was to trace the graduates of CEMBA/CEMPA and the MSc. Industrial Mathematics programmes on the distance learning mode from 2008 to 2010 and graduated in 2010 to 2012 . It was also conducted to generate relevant information that could possibly feed into curricula review.

The study addressed the following research questions:

1. What is the nature of jobs undertaken by the CEMBA, CEMPA and Industrial Mathematics graduates who graduated from 2010 to 2012 ?

2. How relevant are the CEMBA, CEMPA and Industrial Mathematics programmes' curricular to the career experience of the graduates?

3. How do employers assess the usefulness of graduates' knowledge and skills to their career experience?

\section{METHODOLOGY}

\section{Study area}

The study was carried out in seven purposively selected learning centres of KNUST-IDL, namely Accra, Kumasi, Ho, Sunyani, Tamale, Takoradi and Koforidua. These centres were selected because they were the first centres to be established and hence had graduates for the years 2010 to 2012 .

\section{Study design}

The study design was a descriptive survey. This design was deemed appropriate because it facilitated access to the large and scattered graduate population and key informants such as employers and course developers at KNUST. The key informants were interviewed using semi-structured questionnaire.

\section{Sampling and sample size}

The study employed a purposive sampling technique using the list of graduates whose records were available. Graduates identified from the database were used to help identify some other graduates whose records could not be identified. This snowball sampling approach generated additional respondents. Following the table for determining sample size for a given population developed by Krejcie and Morgan (1970) a sample of 315 CEMBA, 113 CEMPA and 175 M.Sc. Industrial Mathematics graduates were selected for the survey. Fifty Employers were purposively selected for the study.

\section{Data collection and analysis}

Data was obtained through multiple sources and techniques. The Primary data were collected using questionnaire and interview guide. The Secondary data were obtained through a desk review of relevant documentation from KNUST-IDL database and reports, KNUST graduation records, curricula reports and course materials. Administration of the questionnaire was through a combination of face-to-face self-reporting and an online version of the questionnaire. Semi-structured interviews were conducted with key-informants who worked directly as supervisors of the graduates.

A database was set up and a coding for the data entry of the completed questionnaires was organised. The data from the questionnaires were entered into MS Excel software and the quantitative data was analysed using IBM SPSS (version 20) with emphasis on frequency counts, percentage distribution, graphical display and measures of central tendency. Thematic coding techniques were used to analyse the qualitative data.

\section{FINDINGS}

The background characteristics of respondents comprised their study center, gender, age and marital status (Table 2). Seven study centers namely: Accra, Kumasi, Ho, Takoradi, Sunyani, Tamale and Koforidua were covered in the study. These study centers had students who graduated between 2010 and 2012. Out of the 450 graduate respondents, it is evident most 
lowed by the Accra center (15.3\%). Regarding gender distribution of respondents, $66.7 \%$ were males while $33.3 \%$ were females.

In all $85 \%$ of the respondents were married. Majority (58.9\%) were within 36-45 age range while $1.1 \%$ were aged 55 years and above. This indicates that majority $(70 \%)$ of the graduates were 36 years old and above thus indicating their maturity. This finding is in agreement with Osei (20 I 0) who found in his study that males dominated the Executive Masters in Business Programme offered in the distance mode. He also found that the majority of the respondents were married and were within the age group 30 to 50 years. A study conducted by Frimpong-Kwapong (2007), indicated that distance learning encourages older people to seek higher education and that it attracted more married participants than single students.

Nature of jobs undertaken by the CEMBA/ CEMPA and Industrial Mathematics graduates

Respondents were asked to indicate their employment status before and after study, sectors of employment and the fields they were working. Out of the 450 graduates, $98.4 \%$ were fully employed before their postgraduate stud-

Table 2: Background characteristics of respondents

\begin{tabular}{|c|c|c|}
\hline Variable & Frequency & Percentage \\
\hline \multicolumn{3}{|c|}{ Centre of Study } \\
\hline Accra & 69 & 15.3 \\
\hline Ho & 48 & 10.7 \\
\hline Koforidua & 41 & 9.1 \\
\hline Kumasi & 129 & 28.7 \\
\hline Sunyani & 52 & 11.6 \\
\hline Tarkoradi & 52 & 11.6 \\
\hline Tamale & 59 & 13.1 \\
\hline \multicolumn{3}{|l|}{ Sex } \\
\hline Male & 300 & 66.7 \\
\hline Female & 150 & 33.3 \\
\hline \multicolumn{3}{|c|}{ Marital Status } \\
\hline Married & 383 & 85.1 \\
\hline Divorce & 1 & 0.2 \\
\hline Single & 60 & 13.3 \\
\hline Widowed & 6 & 1.3 \\
\hline \multicolumn{3}{|l|}{ Age } \\
\hline $25-35$ & 139 & 30.9 \\
\hline $36-45$ & 265 & 58.9 \\
\hline $46-55$ & 41 & 9.1 \\
\hline$>55$ & 5 & 1.1 \\
\hline
\end{tabular}

Source: IDL tracer study field data, 2014 
ies. This implies that students enrolled in the programmes met a major requirement (i.e. 2 years or more field experience) for admission into the programmes. Almost all the graduates (i.e. 99\%) were found to be in full-time employment after their graduate study.

Fig. 1 present the description of the Graduates by sector of employment. The data show that the graduates came from different sectors of employment including the public, private and the Non-Governmental Organisations (NGOs) sectors. The distribution of current sector of employment by graduate by programme of study shows that overall the majority $(69.1 \%)$ were employed in the public sector, and $27.5 \%$ were employed in the private sector while only $2.9 \%$ were employed in the NGO sector.

The majority of CEMBA graduates $(62.6 \%)$ were found in the public sector, followed by the private sector with $33.4 \%$ and only $3.6 \%$ were employed in the NGO sector. For the M.Sc. Industrial Mathematics programme, a higher percentage of graduates $(90.4 \%)$ were in the public sector, $6.8 \%$ were in the private sec- tor and $1.4 \%$ were in the NGO sector. Following a similar pattern, graduates of the CEMPA programme were more attracted to the public sector $(75 \%)$ followed by the private sector $(23.6 \%)$ and the NGO sector $(1.4 \%)$. The specific fields of employment of the graduates by type of programme are presented in Table 3.

Education is by far the most common field of employment of graduates of the three programmes, employing $37.6 \%$ followed by banking and finance with $22.2 \%$ while the security services engaged $15.3 \%$. CEMBA graduates were mainly employed in the banking and finance (29\%) and education (29\%) fields. The education field employed $71 \%$ of the MSc. Industrial Mathematics and $42 \%$ of the CEMPA graduates.

Relevance of the CEMBA/CEMPA and Industrial Mathematics curricular to graduates jobs

Graduates from the various programmes were to indicate how relevant the various content areas of their programmes were to their career experiences.

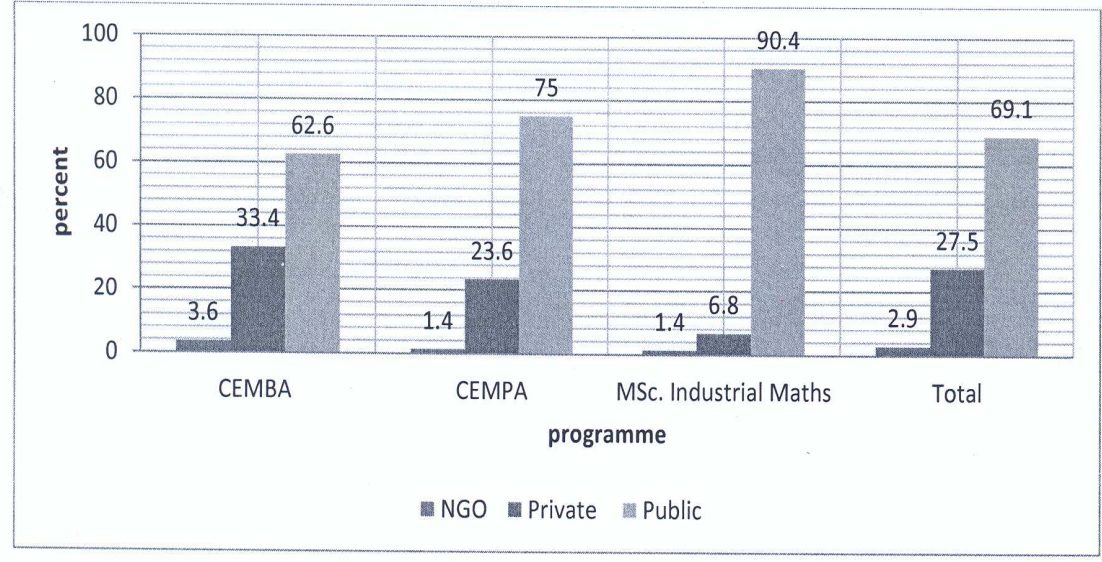

Fig. 1: Distribution of graduates by sector of employment

Source: IDL tracer study field data, 2014

Journal of Science and Technology @ KNUST August 2015 
Table 3: Employment description of graduate respondents

\begin{tabular}{|c|c|c|c|c|}
\hline \multirow[t]{2}{*}{ Field of employment } & \multicolumn{3}{|c|}{ Programme } & \multirow[t]{2}{*}{$\begin{array}{l}\text { Percent of total num } \\
\text {-ber of respondent }\end{array}$} \\
\hline & CEMBA & CEMPA & $\begin{array}{l}\text { M.Sc. Industrial } \\
\text { Mathematics }\end{array}$ & \\
\hline Agriculture and Forestry/Fishery & & 4.2 & 1.4 & 2.7 \\
\hline Banking and Finance & & 4.2 & 12.3 & 22.2 \\
\hline Education & 28.5 & 41.7 & 71.2 & 37.6 \\
\hline Health and social work & 7.5 & 8.3 & 4.1 & 7.1 \\
\hline Industry/Manufacturing & 5.6 & 4.2 & 2.7 & 4.9 \\
\hline Public and Business Administra- & 7.5 & 19.4 & 2.7 & 8.7 \\
\hline tion Services/Security Services & 17.4 & 18.1 & 4.1 & 15.3 \\
\hline Total & 100.0 & 100.0 & 100.0 & 100.0 \\
\hline
\end{tabular}

Source: IDL Tracer study field data, 2014

As indicated in Table 4, most of the CEMBA graduates indicated that all the courses were relevant to their career requirements: Communicating skills (75.9\%); Impacting managerial decision making $(84.1 \%)$; Sales and Marketing (53.4\%); Meeting managerial and administrative demands $(78.7 \%)$; Human resource development (73.8\%); MIS related tasks (55\%); Accounting and Finance $(62.3 \%) ; \quad$ Research/Research Projects $(71.3 \%)$.

Like the CEMBA graduates, the CEMPA graduates found all the courses relevant except sales and marketing where majority $(55.1 \%)$ said it was of little or no relevance to their career. This may be as a result of the fact that most of the CEMPA graduates were not in employment fields that required marketing and sales. However, Public policy which is a core course for CEMPA had the greater majority $(82.9 \%)$ of the CEMPA graduates indicating its relevance to their career.

Employers' assessment of job performance of graduates

Employers were asked to rate the job performance of KNUST-IDL graduates employed in the various fields. An analysis of the perfor- mance of the graduates is presented in Table 5.

The results indicate that job performance of graduates improved after their study. Graduates' 'improved work competence' and 'team working ability' were rated higher after the programme than 'increased knowledge and skills' and 'positive attitude toward work' which were also rated as high after the programme. The higher rating of graduates' job performance indicators after the programme shows a positive effect of the programmes on job performance.

As part of graduates' performance assessment, employers were also required to report on the strengths and weaknesses of the KNUST-IDL graduates. The responses on strengths are presented in Table 6 and that of weaknesses in Table 7.

The highest ranking on strengths of graduates highlighted by employers was the knowledge and competency of graduates mentioned by 30 of the employers interviewed. Next in rank was hard work and commitment of graduates. Effective time management and Good leadership skills were ranked the least of the strengths of graduates. From Table 7, the ma- 
Table 4: Relevance of programme to carrier experience

\begin{tabular}{|c|c|c|c|}
\hline \multirow[t]{3}{*}{ Content area } & \multicolumn{3}{|c|}{ Responses: No (\%) } \\
\hline & Not Relevant & Somewhat & Relevant \\
\hline & & Relevant & \\
\hline \multicolumn{4}{|l|}{ CEMBA } \\
\hline Communicating skills & $12(4.1)$ & $59(20)$ & $224(75.9)$ \\
\hline Impacting managerial decision making & $6(2)$ & $42(14)$ & $253(84.1)$ \\
\hline Sales and Marketing & $53(17.9)$ & $85(28.7)$ & $158(53.4)$ \\
\hline $\begin{array}{l}\text { Meeting managerial and } \\
\text { administrative demands }\end{array}$ & $8(2.6)$ & $56(18.6)$ & $237(78.7)$ \\
\hline Human resource development & $11(3.7)$ & $68(22.5)$ & $223(73.8)$ \\
\hline MIS related tasks & $17(5.6)$ & $119(39.4)$ & $166(55)$ \\
\hline Accounting and Finance & $29(9.6)$ & $85(28.1)$ & $188(62.3)$ \\
\hline Research/Research Projects & $27(8.9)$ & $60(19.8)$ & $216(71.3)$ \\
\hline \multicolumn{4}{|l|}{ CEMPA } \\
\hline Communicating skills & $1(1.5)$ & $14(20.9)$ & $52(77.6)$ \\
\hline Impacting managerial decision making & $1(1.4)$ & $14(20)$ & $55(78.6)$ \\
\hline Sales and Marketing & $16(23.2)$ & $22(31.9)$ & $31(44.9)$ \\
\hline $\begin{array}{l}\text { Meeting managerial and } \\
\text { administrative demands }\end{array}$ & $1(1.5)$ & $16(23.5)$ & $51(75)$ \\
\hline Human resource development & $0(0)$ & $16(23.2)$ & $53(76.8)$ \\
\hline MIS related tasks & $8(12.3)$ & $18(27.7)$ & $39(60)$ \\
\hline Public policy & $4(5.7)$ & $8(11.4)$ & $58(82.9)$ \\
\hline Research/Research Projects & $4(5.6)$ & $13(18.1)$ & $55(76.3)$ \\
\hline \multicolumn{4}{|l|}{ M.Sc. Industrial Mathematics } \\
\hline Mathematical models & $7(9.6)$ & $19(26)$ & $47(64.4)$ \\
\hline Quantitative techniques & $9(12.8)$ & $26(37.1)$ & $35(50)$ \\
\hline Computational and numerical methodologies & $7(9.6)$ & $19(26)$ & $47(64.4)$ \\
\hline Communicating results & $17(25.8)$ & $17(25.8)$ & $32(48.5)$ \\
\hline Interpreting and improving results & $5(7.3)$ & $26(38.2)$ & $37(54.4)$ \\
\hline Impacting managerial decision making & $16(24.6)$ & $23(35.4)$ & $26(40)$ \\
\hline Research/Research Projects & $12(16.4)$ & $20(27.4)$ & $41(56.2)$ \\
\hline
\end{tabular}

Note: Figures in parenthesis are percentages

Source : IDL Tracer study field data, 2014

Table 5: Job performance rating of graduates by supervisors

\begin{tabular}{lcc}
\hline Performance indicators & Rating before studies & Rating after studies \\
\hline Positive attitude toward work team & 3.24 & 4.11 \\
working ability & 3.54 & 4.63 \\
Improved work competence & 3.67 & 4.98 \\
Increased knowledge and skills & 3.76 & 4.4 \\
\hline
\end{tabular}

Source: IDL Tracer

Note: Performance rating scale: $1=$ very low; $2=$ Low $; 3=$ average $; 4=$ high $; 5=$ very high 
Table 6: Strengths of graduates

\begin{tabular}{lcc}
\hline Strength & Frequency* $^{*}$ & Rank \\
\hline Knowledgeable and competent & 30 & 1 \\
Hardworking and committed & 24 & 2 \\
Team player & 14 & 3 \\
Good interpersonal and communication skills & 13 & 4 \\
Creative and innovative & 10 & 5 \\
Effective time management & 7 & 6 \\
Good leadership skills & 4 & 7 \\
\hline
\end{tabular}

Source: IDL Tracer study field data, 2014

Note: $*=$ multiple responses

Table 7: Weaknesses of graduates

\begin{tabular}{lcc}
\hline Weakness & Frequency* & Rank \\
\hline No known weakness & 34 & 1 \\
Reserved/not outspoken & 7 & 2 \\
Not good at meeting deadlines & 3 & 3 \\
Over deliberative and critical & 3 & 3 \\
Indecisive & 1 & 5 \\
\hline
\end{tabular}

Source : IDL Tracer study field data, 2014

Note: $*$ multiple responses

jority of the employers did not associate any weakness to the graduates. However 'reserved/ not outspoken' was the higher ranked weakness by the employers.

\section{CONCLUSION AND RECOMMENDA- TIONS}

The tracer study has provided an opportunity for KNUST-IDL to obtain the necessary feedback from its graduates. The study revealed that KNUST-IDL was making a significant contribution to its learners by providing opportunities to improve their knowledge, skills and competencies to perform better in their careers. Graduates found majority of the course contents of their programme relevant to their career requirements.
The survey also revealed that job performance of graduates had improved after their studies. Job performance indicators such as 'improved work competence' and 'team working ability' were rated 'very high', while 'increased knowledge and skills' and 'positive attitude toward work' were rated 'high' after graduates' studies.

Based on the findings from the study, it is recommended that KNUST-IDL use graduates' feedback as contained in this study to improve the quality of the study programmes. KNUSTIDL can also use the information gathered to adapt their courses to the demands of the labour market.

\section{ACKNOWLEDGEMENT}

The authors are grateful to the KNUST-IDL 
for providing funds for the study. We also acknowledge the assistance of the senior members of KNUST-IDL and the Department of Mathematics-KNUST.

\section{REFERENCES}

Aina, L.O. and Moahi, K. (1999). "Tracer study of the Botswana library school graduates," Education/or Information, 17(3): 215244.

Anyanwu, G. A. (2000). Graduates' Transition from Study to Employment: A Study of the Arts and Agriculture Graduates of University of Nigeria in the World of Work. A study report submitted to the Association of African Universities

Balingbing, A. B. (2014). Tracer Study of BSc in Information Technology (BSIT) Graduates of Camarines Sur Polytechnic Colleges, Nabua, Camarines Sur from 2004 to 2010. Asia Pacific Journal of Multidisciplinary Research, 2(4). Accessed from http// www.academia.edu/8002452 on June, 2015.

Boaduo, N. A. P., Mensah, J., and Babitseng, S. M. (2009). Tracer study as a paradigm for the enhancement of quality course programme development in higher education institutions In South Africa. Paper presented at the Educational Colloquium, University of North-West, Potchefstroom, South Africa, 20-21 August 2009. Accessed from http:// webreg.uzulu.ac.za:8090/itsquery/ showQuaIEnrollment.jsp.on 15th June, 2015.

Bolton, T. and Hyland, T. (2003). Implementing Key Skills in Further Education: perceptions and issues. Journal of Further and Higher Education, 27(1): 15-26.

Dickinson, M. (2000). Giving undergraduates managerial experience. Education + Training, 42(3): 159-169.

Frimpong-Kwapong, O. A. T. (2007). Widening access to tertiary education for women in Ghana through distance education. Turkish Online Journal of Distance Education, 8 (4): 65-79.

Genoni, P., Exon, M. and Farrelly, K. (2000). 'Graduate employment outcomes for qualifying library and records management courses at Curtin University of Technology', Australian Library Journal, 49(3): 245-258.

Gines, A. C. (2004). Tracer Study of PNU (Philippine Normal University) Graduates. American International Journal of Contemporary Research. 4(3): 81-98.

Krejcie, R. Y. and Morgan, D.W. (1970). Determining sample size for research activities. Educational and Psychological Measurement, 30: 607-610.

Millington, C. (2003). The Use of Tracer Studies for Enhancing Relevance and Marketability Online and Distance Education. Accessed from http://wikieducator.org/images/ e/ell PID _ 424.pdf on $1^{5 t}$ June, 2015.

Osei, C. K. (2010). Perceptions of students towards use of distance learning: The case in an executive masters business programme in Ghana. Online Journal of Distance Learning Administration, 13(2). Accessed from http://www.westga.edu/ $\sim \mathrm{distance/ojdla/s} \mathrm{ummer} 132 /$ osei132.htmlon $2^{\text {nd }}$ June, 2015.

Schomburg, H. (2003). Handbook for Graduate Tracer Studies: Centre for Research on Higher Education and Work, University of Kassel, Germany. Accessed from http:// www.qtafi.de/handbook v2.pdf.on $15^{\text {th }}$ July, 2014.

Stilwell, C. (2004). Alumni perception of a post graduate information and library science education programme at the University of Natal, South Africa. South African Journal of Libraries and Information Science, 70 (1): 20-29 
Tracer study of IDL graduates in KNUST... 99

WECARD Report (2010). Report on Tracer http://ruforum.org/sites/default/fiIes/Tracer\% Study of Agricultural Graduates in Ghana. November 2010. Accessed from 20Study\%20Ghana.pdf on $22^{n d}$ May, 2015. 